\title{
Morph Composition Matters in the Gouldian Finch (Chloebia gouldiae): Involvement of Red-Headed Birds Increases Vigilance
}

\author{
Claudia Mettke-Hofmann (D)
}

check for updates

Citation: Mettke-Hofmann, C. Morph Composition Matters in the Gouldian Finch (Chloebia gouldiae): Involvement of Red-Headed Birds Increases Vigilance. Birds 2021, 2, 404-414. https://doi.org/10.3390/ birds2040030

Academic Editor: Jukka Jokimäki

Received: 15 October 2021

Accepted: 23 November 2021

Published: 25 November 2021

Publisher's Note: MDPI stays neutral with regard to jurisdictional claims in published maps and institutional affiliations.

Copyright: (C) 2021 by the author. Licensee MDPI, Basel, Switzerland. This article is an open access article distributed under the terms and conditions of the Creative Commons Attribution (CC BY) license (https:// creativecommons.org/licenses/by/ $4.0 /)$.
School of Biological \& Environmental Sciences, Liverpool John Moores University, Liverpool L3 3AF, UK; C.C.Mettke-Hofmann@ljmu.ac.uk

Simple Summary: Animals spend considerable time looking out for predators (vigilance), which takes time away from other activities, such as foraging. By joining groups, animals reduce the time spent being vigilant. Interestingly, in mixed species groups, vigilance is often further reduced due to lower competition between individuals and combinations of different strategies to scan the environment. However, little is known about whether similar effects occur in species that consist of different colour morphs in the same population. Understanding how morphs affect each other is important in explaining the persistence of different morphs in a population. The aim of the study was to investigate whether red-headed and black-headed Gouldian Finches showed differences in vigilance and whether morph combination, e.g., mixed-morph groups, affected vigilance as in mixed-species groups. Irrespective of head colour, Gouldian Finches changed their vigilance the more unfamiliar a situation became (familiar-changed-unfamiliar environment). This demonstrated that birds use different scan strategies depending on the environment; frequent, superficial scans in familiar surroundings and fewer, more exploratory head movements in unfamiliar situations. Moreover, pure black-headed pairings were less vigilant than pairings involving red-headed birds. Red-headed birds are more aggressive and may elicit higher vigilance in other birds.

Abstract: Animals invest in costly vigilance to detect threats. Joining groups reduces these costs, which can be further reduced in mixed-species assemblages. In colour-polymorphic species, morphs often experience different predation pressure and vary in a variety of traits. However, little is known about differences in vigilance or how group composition affects vigilance. The aim was to investigate whether higher conspicuousness increased vigilance and whether vigilance was reduced in mixed-morph groups like in mixed-species assemblages. I tested vigilance in the colourpolymorphic Gouldian Finch (Chloebia gouldiae). Same sex pairs of different age and of either pure (red-red or black-black) or mixed head colour were exposed to three contexts (familiar, changed and novel environment) and head movements were recorded. All birds reduced the frequency of head movements with increasing novelty, indicating different vigilance strategies (switching from a searching to a tracking strategy) depending on the situation. While vigilance did not differ between morphs, morph composition mattered. Black-headed pairs made fewer head movements than mixedhead colour pairs. Results indicated that conspicuousness did not affect vigilance, possibly due to existing adaptations to reduce predation risk. However, whenever red-headed birds were involved, vigilance increased either because of higher group conspicuousness or prevalence of aggression.

Keywords: visual exploration; polymorphism; vigilance; group composition; head movements; bird; estrildidae

\section{Introduction}

Vigilance is an important anti-predator behaviour that incurs costs because it often cannot be combined with other activities, such as foraging (e.g., [1]). By joining groups, 
individuals can reduce the time invested in vigilance (e.g., [2]) and increase safety (manyeyes hypothesis [3]; dilution effect [4]). Interestingly, vigilance-and, therefore, costs-are often reduced even further in mixed-species assemblages [5-8]. Reasons for this can include less foraging competition, requiring less tracking of nearby companions [9,10], but more importantly, different perception abilities can be combined resulting in earlier detection of threats [11].

Vigilance is generally assessed in a foraging context by measuring the frequency and duration of head-up [1,12-14] or the interscan interval [14,15]. A foraging context is used because foraging often prevents vigilance. Studies have found that a higher frequency of head-up positively correlates with predator detection [16]. Likewise, scan frequency is higher in novel environments [17,18], when further away from cover [19] or at the periphery of groups [20], when in smaller groups [12,21] and once a predator has been detected $[13,17]$.

More recently, head movements (primarily horizontal in contrast to primarily vertical head-ups) have been used to measure vigilance because this method provides more information about the strategies used when scanning the environment [22]. The frequency of (horizontal) head movements gives information about how often an individual changes its visual field to enhance visual coverage (i.e., brings the fovea, which is the area of higher visual acuity, in contact with a different area of the environment). Head movements also allow estimation of distances to objects and exploration of a visual target, such as a predator, objects or conspecifics [22]. Two principle strategies have been proposed [23]; (1) visual search is characterised by a high frequency of head movements to cover a large area quickly and detect any threats. (2) Visual tracking, in contrast, consists of a lower frequency of head movements, which allows tracking of targets (e.g., predators or conspecifics) and collecting of information about distance, identity and movements of the target [23]. A high frequency of head movements has been observed after a predator event [24], in birds at the periphery of a flock [25], in novel environments [26] and in small groups [27,28], indicating that this corresponds to increased vigilance.

Few studies have investigated intraspecific differences in vigilance, but age has been shown to have an effect-albeit with sometimes opposing outcomes. Most studies find lower vigilance in young animals due to either higher nutritional needs (i.e., trading off vigilance and foraging opportunities) [29,30] or inexperience looking out for threats [31]. However, some studies have found higher vigilance in juveniles due to their inherently higher vulnerability [32]. Interestingly, such state-dependent differences in vigilance can be situation-specific. For example, juvenile and adult yellow-bellied marmots (Marmota flaviventris) had similar vigilance levels under baseline conditions but differed under threat conditions, with juveniles being more vigilant [32]. Higher vulnerability linked to state may also explain the higher scan rates in subordinate and pregnant rabbits (Oryctolagus cuniculus) as compared to dominant or non-pregnant individuals [30], and in adult male yellow-bellied marmots as compared to females [32]. Furthermore, consistent individual differences (personality) in vigilance have been found in Eastern grey kangaroos (Macropus giganteus) [10] and birds [33-35].

Little research has been done on differences in vigilance linked to colour polymorphism, which describes the co-existence of at least two colour-morphs in the same population [36]. Morphs differ in a variety of behaviours (aggression, neophilia, mating strategies, anti-predator behaviour) [37-41] and often experience different predation pressure $[36,42,43]$. This may favour the evolution of divergent vigilance patterns. In support of this, Pine Siskins (Spinus pinusv) with a larger black bib, which were also more aggressive and explorative, and thus have a higher risk of predation, had a higher head-up frequency than individuals with a smaller bib [15]. In Eastern grey squirrels (Sciurus carolinensis) the stress-prone grey morph tended to show more vigilance following playback of a nonthreatening bird call than the stress-resistant black morph [44]. Similarly, nestlings of darker spotted Barn Owl (Tyto alba) mothers looked more often to the nest entrance than nestlings from lighter spotted mothers indicating higher vigilance linked to sibling compe- 
tition [45]. However, next to nothing is known about how morph composition may affect vigilance. Given that vigilance is often reduced in mixed-species groups, mixed-morph groups may also have reduced vigilance as compared to same-morph groups, as morphs may pay attention to different cues. Whether this would benefit all morphs equally is currently unclear. The aim of the study was to investigate whether colour morphs of the Gouldian Finch (Chloebia gouldiae) differed in their vigilance across situations and whether morph composition affected that vigilance. Differences in vigilance could help to better understand the evolution and persistence of colour morphs.

Gouldian Finches inhabit tropical savannah grassland in North Australia [46] with populations consisting of about $70 \%$ black-headed birds, $30 \%$ red-headed birds and less than $1 \%$ yellow-headed birds in both sexes [47]. This distinct non-melanin-based polymorphism is very different from the melanin-based gradual polymorphism observed in the Barn Owl, Siskin and squirrels mentioned above. Previous research in the laboratory has shown that Gouldian Finches' head colour signals their personality; red-headed birds are more aggressive but less explorative and more risk-averse than black-headed birds [48]. Higher risk-taking in black-headed females has been confirmed in the wild [49]. Differences between morphs can be explained with the higher conspicuousness of the red morph [48]. Moreover, the red-headed morph seems to benefit from mixing with the black-headed morph as red-headed birds are prone to social stress when the proportion of their own morph is experimentally increased [50]. However, currently, little is known about how black-headed birds may benefit from mixing with red-heads. One possibility could be that red-headed birds are more vigilant due to their higher conspicuousness, which would benefit black-headed birds, particularly when engaged in exploration or risky situations. Aside from head colour, age has been found to affect responses to unfamiliar situations in Gouldian Finches, with younger birds being more explorative [40].

In the current study, we investigated the effects of head colour, head colour composition and effects of age on vigilance. We recorded vigilance in different situations, ranging from a familiar situation, to a changed situation and a new situation, simulating different degrees of risk. Vigilance was recorded as horizontal head movements to capture different scanning strategies used. The following predictions were made.

(1) Vigilance differs between situations, with higher vigilance corresponding to more novel situations.

(2A) Morph affects vigilance, with red-headed birds being more vigilant than blackheaded birds due to their higher conspicuousness.

(2B) Alternatively, vigilance is similar in both colour morphs because the black-heads' risk-prone behaviour may outweigh their better camouflage.

(3) Morph composition affects vigilance, with mixed-morph groups displaying lower vigilance than single-morph groups, as the two morphs may complement each other in their vigilance similar to mixed-species assemblages.

(4) Age affects vigilance, with younger birds being more vigilant due to their higher exploration propensity.

\section{Materials and Methods}

Thirty Gouldian Finches took part in the experiment: 15 males (7 black-headed, 8 red-headed) and 15 females (8 black-headed, 7 red-headed). Twenty-four birds were tested over a period of three weeks in December 2017. To increase sample sizes, a further six birds were added from a nearly identical experiment conducted in the same cages in November 2018 (see details below). All birds originated from ten bird breeders purchased over several years. Birds were at least six months in the current holding conditions before testing. Ages ranged from one to seven years.

The Gouldian Finches were kept in mixed sex, age and head colour groups of about six birds. Cage dimensions were $120 \mathrm{~cm} \times 80 \mathrm{~cm} \times 100 \mathrm{~cm}$ (length $\times$ depth $\times$ height) with a wire mesh front and ceiling and contained natural twigs and perches. Food consisted of a mixture of Blattner Amadine Zucht Spezial (Gouldamadine), Blattner Astrilden Spezial 
and Blattner rote Mannahirse (Blattner Heimtierfutter, Ermengerst, Germany). Blattner bird grit was provided separately, as were eggshells. Cages contained water dispensers and a bath. The light regime was $13 \mathrm{~h}$ light to $11 \mathrm{~h}$ dark.

\subsection{Experimental Procedures}

Experiments were conducted in a separate room containing six cages $(120 \mathrm{~cm} \times 70 \mathrm{~cm}$ $\times 100 \mathrm{~cm}, \mathrm{~L} \times \mathrm{D} \times \mathrm{H}$ ) arranged in two rows of three cages. Walls consisted of wood, except the front and ceiling, which were wire mesh. Two perches were located on the left and right side of the cage two thirds of the way from the ground and a third perch ran perpendicular to the other two along the front of the cage. Food and water were provided in feeders and drinkers at the front of the cage. A camera was permanently mounted on a tripod one meter away from the front of the cage for data recording. The arrangement of the cages prevented birds seeing each other but they could hear each other. Only four of the six experimental cages were used for this experiment due to logistical reasons. Experiments were conducted over a six-day period testing four groups at the same time (= one batch) with the next batch of birds being moved into the experimental cages two days after the preceding group had finished.

As Gouldian Finches are highly social, birds were tested in same-sex pairs in different head colour combinations (seven red-headed pairs, five black-headed pairs, five mixedhead colour pairs balanced across sex). The only exceptions were one red-headed pair and one mixed head colour pair that were tested in a mixed sex pairing due to unequal numbers of head colours within sexes. Head colour combinations and sexes were balanced within and across batches.

The 24 birds tested in 2017 went through the following experiments. Vigilance was investigated in three different situations; (a) novel environment (at release into the experimental cage, day 1), (b) familiar environment (after 5 days of habituation) and (c) changed environment 1 (day 5) and changed environment 2 (day 6). Changes in the environment were created by placing a toy animal in front of the cage $40 \mathrm{~cm}$ away from the front wire at the height of the perches either on the left or right side. The position of the toys depended on the arrangement of the cages; toys were presented on the side furthest away from the next cage with a bird (to ensure that birds in the other cage could not see the toys). Toy animals used were a panda bear $(17 \mathrm{~cm} \times 9 \mathrm{~cm} \times 8 \mathrm{~cm})$ and a penguin $(15 \mathrm{~cm} \times 8 \mathrm{~cm}$ $\times 8 \mathrm{~cm}$ ) mounted on a tripod. Both toys were black and white, with the penguin having a yellow beak. Toys did not resemble any natural predators of the Gouldian Finch (birds of prey and snakes). The panda bear was the first object in 8 pairings ( 3 pure black-headed, 3 pure red-headed pairs and 2 mixed head colour pairs) and the penguin in four pairings (1 pure black-headed pair, 1 pure red-headed pair, 2 mixed head colour pairs). Experiments started at $1000 \mathrm{~h}$ and lasted for one hour each. Data were recorded by digital video cameras using GeoVision 1480 (GeoVision Inc., Taipei, Taiwan). for later analysis.

The additional 6 birds tested in 2018 went through exactly the same procedure as the birds in 2017 with the exception of the changed environment on day 5 and 6 . Instead of the toy animals presented outside, the 2018 birds were tested on object neophobia (novel object beside familiar feeder) and object neophilia (novel object at a neutral location in the cage). For the current study, only the data for the novel and familiar situation were included in the analysis. It should be noted that four of the six additional birds had partners already tested in 2017. The responses of these partner birds were not included as they were already represented in the dataset. Experiences with the cages a year ago were unlikely to have affected responses as reactions to unfamiliar situations usually fully recover after non-exposure of three to four weeks [51,52].

Birds were released into the cage and video recording started immediately to collect data about vigilance in the novel environment (situation a). After one hour, recording was stopped, and birds had until day 5 to habituate to the environment. On day 5, vigilance was recorded from $1000 \mathrm{~h}$ to $1100 \mathrm{~h}$ in the now familiar environment (situation $\mathrm{b}$ ). For the 2017 birds only, at $1100 \mathrm{~h}$, one of the unfamiliar toy animals was positioned outside the 
cage and vigilance in a changed environment (situation c) was recorded. Situation c) was repeated on day 6 with the other toy animal. Afterwards, birds were moved back into their holding cages and the next batch of eight birds was tested.

\subsection{Data Analysis}

I used head movement as a measure of vigilance [22]. A head movement was recorded when the head visibly moved. For each individual, I extracted the frequency of head movements in each situation. The frequency of head movements is inversely related to the duration of looking in a particular direction [25].

All analyses were conducted with SPSS v. 26. The full data set is available in the Supplementary Table S1. Frequency of head movements in the two changed environments (panda bear and penguin; situation c) were correlated with each other (Pearson Correlation rs $=0.53, n=24, p=0.010$ ). For analyses, I used the mean frequency of head movements of the two changed environment situations. Sample size was $n=30$ for the familiar and novel situation and $n=24$ for the changed situation. Frequencies of head movements were normally distributed and General Linear Mixed models (GLMM) used with an identify link function to account for the repeated measurements. The level of analysis was the individual (subject). Degrees of freedom were calculated using the Satterthwaite method due to unequal sample sizes. A series of models were built to test for effects of different variables and interactions. Akaike information criterion (AIC) was used to select the model with the best fit starting with a basic model and then adding additional variables and interactions. The basic model consisted of three fixed factors (situation, head colour morph and age class), two covariates (partner head colour morph and sex) and two interaction terms (head colour morph $\times$ partner head colour morph and head colour $\times$ sex). The three fixed effects allowed for the addressing of predictions 1, 2 and 4, while the interaction term between head colour morphs allowed for prediction 3 about group composition and the interaction head colour $\times$ sex to account for any differences in responses between sexes. Three age classes were formed ((1) one to two years $(n=12),(2)$ three to four years $(n=9)$, (3) five to seven years $(n=9))$ to have sufficient sample sizes in each class. Age class was not included as an interaction term due to small sample sizes. More complex models included interaction terms with situations and different combinations of two interactions.

\subsection{Ethical Note}

Experiments were conducted in accordance with The Association for the Study of Animal Behaviour (ASAB) ethical guidelines (Guidelines for the use of animals 2018) and were non-invasive in nature. Experiments were approved by the University Ethics Committee.

\section{Results}

The best model retaining the most information was the basic model with the interaction term age class $\times$ situation added (Table 1 ). The GLMM (Table 2) revealed that the main factor situation was significant $\left(\mathrm{F}_{2,67}=67.804, p<0.001\right)$. The frequency of head movements decreased the more novel a situation became (familiar-changed-novel; Figure 1). Post hoc tests revealed that the frequency of head movements differed significantly between all three situations (paired $t$-test: familiar-changed $(n=24)$ : $t=4.507, p<0.001$; familiar-novel $(n=30): t=10.004, p<0.001$, changed-novel $(n=24): t=-5.803, p<0.001)$. Additionally, the interaction term head colour morph $\times$ partner head colour morph was significant $\left(F_{2,67}=3.443, p=0.038\right.$; Figure 2). When black-headed birds were partnered with another black-headed bird, the focal bird made significantly fewer head movements than when partnered with a red-headed bird $(t=-2.327, p=0.023)$. In contrast, partner head colour had no significant effect on the frequency of head movements in red-headed birds $(t=1.200$, $p=0.235$ ). No other factors or interactions were significant (Table 2). 
Table 1. Model selection outcome using Akaike information criterion (AIC) comparing vigilance in Gouldian Finches with respect to head colour, partner head colour, age class and sex in different situations.

\begin{tabular}{lcc}
\hline \multicolumn{1}{c}{ Model } & AIC & Diff $^{\mathbf{1}}$ \\
\hline Basic model $^{2}+$ age class $\times$ situation & 1018.619 & \\
Basic model + partner colour morph $\times$ situation & 1053.297 & 34.678 \\
Basic model + partner colour morph $\times$ situation & 1112.279 & 93.66 \\
+ sex $\times$ situation & 1134.826 & 116.207 \\
Basic model + sex $\times$ situation & 1143.323 & 124.704 \\
Basic model + age class $\times$ situation + sex $\times$ situation & 1175.461 & 156.842 \\
Basic model & 1226.478 & 207.859 \\
Basic model + partner colour morph $\times$ situation & 1247.169 & 228.55 \\
+ age class $\times$ situation & 1267.519 & 248.9 \\
Basic model + colour morph $\times$ situation & & \\
Basic model + partner colour morph $\times$ situation & colour morph $\times$ situation &
\end{tabular}

${ }^{1}$ Diff: Difference in AIC to best model (italics); ${ }^{2}$ Basic model: Situation + colour morph + age class + partner colour morph $(C)+\operatorname{sex}(C)+$ colour morph $\times$ partner colour morph + colour morph $\times$ sex; : variable entered as covariate.

Table 2. General Linear Mixed model outcome of best model (see Table 1).

\begin{tabular}{lcccc}
\hline Variables & F-Value & Df1 & Df2 & $p$ \\
\hline Corrected model & 13.927 & 13 & 67 & $<0.001$ \\
Situation & 67.804 & 2 & 67 & $<0.001$ \\
Colour morph & 0.058 & 1 & 67 & 0.810 \\
Age class & 0.448 & 2 & 67 & 0.641 \\
Colour morph $\times$ partner colour morph & 3.443 & 2 & 67 & 0.038 \\
Colour morph $\times$ sex & 0.896 & 2 & 67 & 0.413 \\
Age class $\times$ situation & 1.637 & 4 & 67 & 0.175 \\
\hline
\end{tabular}

Df1 and Df2 = degrees of freedom.

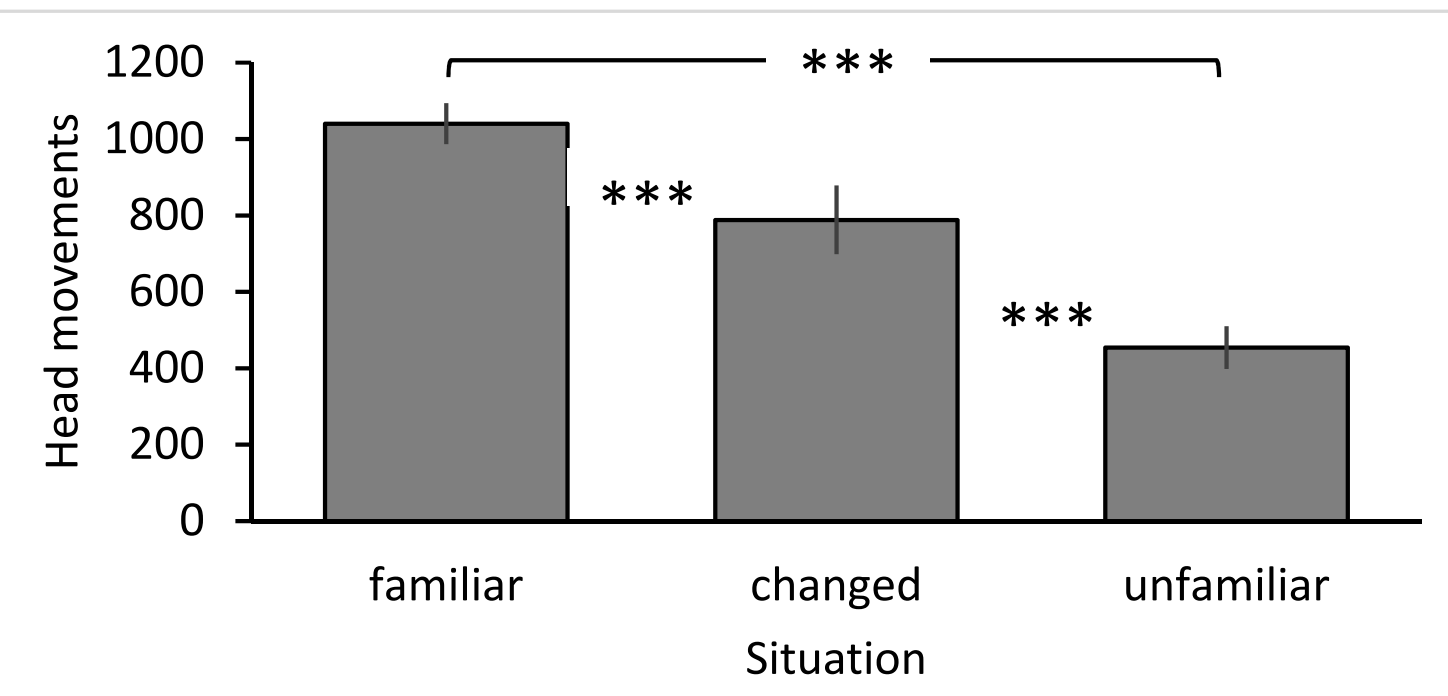

Figure 1. Vigilance of Gouldian Finches in relation to situation. Mean \pm SE frequency of head movements in familiar, changed and unfamiliar situations; ${ }^{* *} p<0.001$. 


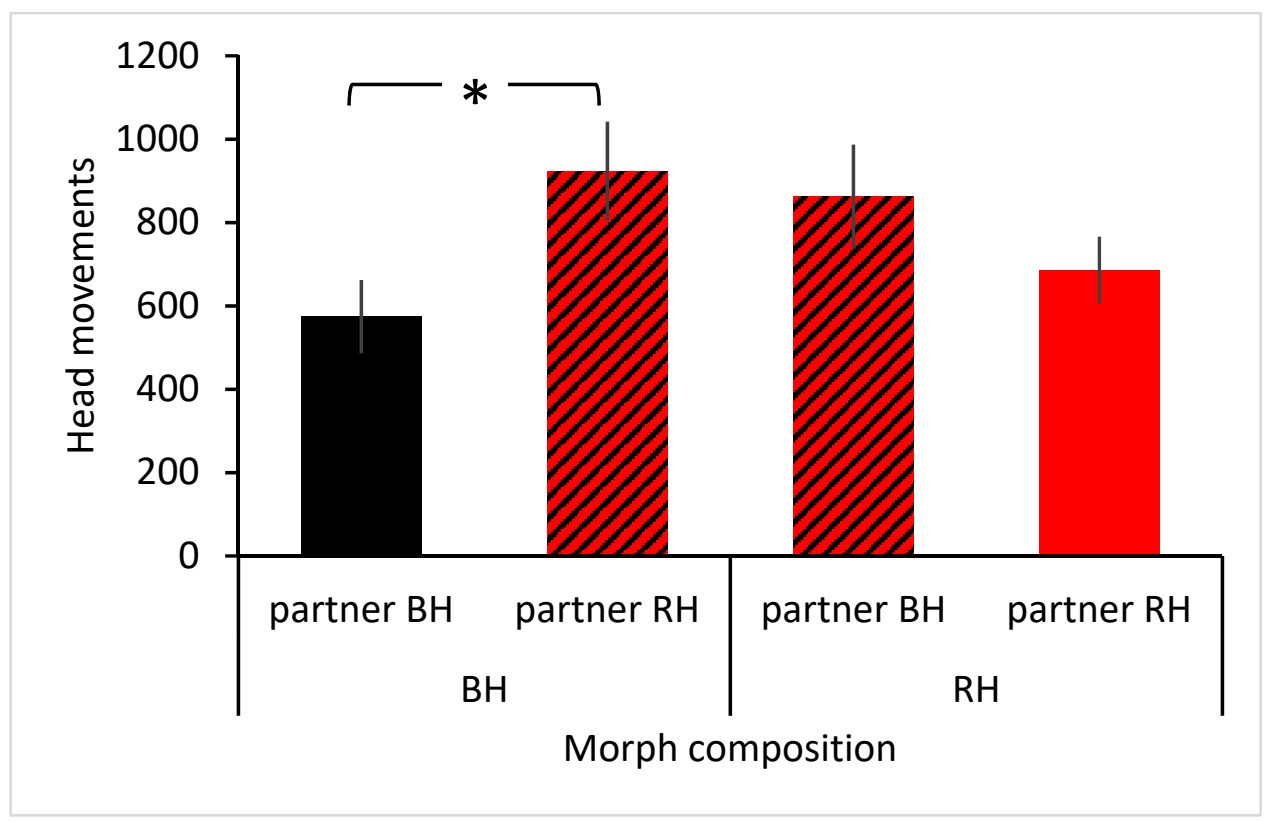

Figure 2. Effect of morph composition on vigilance in Gouldian Finches. Mean $\pm \mathrm{SE}$ of frequency of head movements for black-headed birds $(\mathrm{BH})$ paired with another black-headed bird (partner $\mathrm{BH}$; black bar) or a red-headed bird (partner RH; hatched red-black bar) and for red-headed birds (RH) paired with a black-headed bird (hatched red-black bar) or another red-headed bird (red bar). ${ }^{*} p<0.05$.

\section{Discussion}

Vigilance differed between the three tested situations, with a decrease in head movements from the familiar to the changed to the unfamiliar situations. Moreover, irrespective of situation, morph composition played a role: black-headed birds partnered with another black-headed bird performed fewer head movements than when partnered with a redheaded bird, whereas there was no effect of partner head colour on the frequency of head movements in red-headed birds.

I predicted that vigilance would differ between the three situations, with higher vigilance in the changed and unfamiliar situations (Prediction 1). Gouldian Finches indeed discriminated between the three situations and responded with different vigilance patterns. However, responses were the opposite to what had been expected. Most head movements occurred in the familiar situation. This was surprising, as several studies have shown that scan frequency and head movements increase in unfamiliar situations $[17,26]$ or when at the periphery of a flock, i.e., in more exposed conditions [25]. A high frequency of head movements is consistent with a visual search strategy [23]. Frequent head movements allow coverage of a large visual area in a short period of time, which is positively correlated with a high rate of predator detection [22]. However, it may also be indicative of a strategy to rely more on individual, rather than social, information [23]. The frequency of head movements dropped considerably in the changed environment and even more in the unfamiliar environment, consistent with a visual tracking strategy [23]. Tracking allows collection of information about an object, its distance, and properties, as attention is directed for longer on one aspect in the environment [23]. In the changed situation, the lower frequency of head movements allowed the Gouldian Finches to focus for longer on a particular part of their environment, thereby collecting information about the toy objects. This helped to reduce uncertainty [53] and assess their potential danger. Aside from this exploratory component, the birds seemed to keep an eye on the toy objects as they maintained the lower frequency of head movements throughout the experiment. Focusing more on the one aspect that has changed is adaptable and results in fewer head movements directed towards the change. Similarly, the Gouldian Finches collected information about 
the novel environment in the unfamiliar situation by looking for longer in one direction to visually investigate aspects in the environment.

Interestingly, head movements decreased in order from the familiar to the most unfamiliar, i.e., from an environment of least novelty to highest novelty. This further supported information gathering as the birds may have visually explored their environment more intensely the more novel the situation became to reduce uncertainty [53]. Alternatively, several studies have shown that neophobia, the fear of novelty, increases the more deviating an environment is from what an animal has experienced before-or from innate biases $[51,52,54]$. The increasing novelty of the situation may have caused the Gouldian Finches to become more cautious, as novelty can also mean danger. In the wild, when Gouldian Finches land in a tree, they sit quietly without any movements (pers. obs. $\mathrm{CMH}$ ). This may help them camouflage better with the environment. They may do the same in captivity, resulting in fewer head movements. Beauchamp [6] mentioned that, in urban environments, vigilance is often reduced when there is a disturbance, possibly due to reduced predation. The safe captive environment may have had a similar effect on the Gouldian Finches. Finally, it would be interesting to investigate whether responses would change when larger groups were considered, as group size has been shown to change vigilance $[12,21,55]$.

Conspicuousness has been shown to increase predation risk (e.g., [56]). Higher vigilance can counteract this increased risk [16]. It was, therefore, expected that the more conspicuous red-headed birds would be more vigilant than black-headed birds (prediction 2A). This was not the case, as morphs did not differ in their vigilance. This contrasted with other studies on colour polymorphic species $[15,44,45]$. These species showed a gradual, melanin-based polymorphism, whereas Gouldian Finches have a distinct non-melaninbased polymorphism. Existing behavioural adaptations in the Gouldian Finch may alleviate differences in predation risk between the morphs. Risk-aversiveness and lower exploration in the red-headed morph $[40,48,49]$ may reduce predation-risk for this morph sufficiently, without the need for higher vigilance. This supports hypothesis $2 \mathrm{~B}$, which predicted no differences in vigilance between colour morphs due to the higher risk-taking behaviour of the black morph. Interactions between behaviour, morph and vigilance have been found in other species, albeit with inconsistent patterns. In Pine Siskins, the darker morph was more vigilant and bolder [15], whereas in Barn Owls, nestlings of darker spotted mothers were more vigilant, but shyer, showing more passive antipredator behaviour than nestlings from lighter spotted mothers [45,57]. In contrast, the lighter-coloured grey morph in squirrels tended to be more vigilant and shyer than the black morph [44]. This indicates complex and varying interactions between vigilance, morph and boldness across species. As vigilance comprises looking out for predators and conspecifics, more research is needed about which causes affect vigilance.

Irrespective of situation, the composition of head colours affected vigilance. The frequency of head movements was lowest when a black-headed bird was partnered with another black-headed bird. This was in contrast with prediction 3, which predicted lower vigilance in mixed morphs. In mixed species assemblages, vigilance is often reduced due to different perception properties of the species involved, which allow earlier detection of predators $[5,6,11,58,59]$. In the current study, perception properties of morphs were likely the same. However, Gouldian Finches may consider group composition with respect to predation risk, as head movements were higher whenever red-headed birds were involved. Red-headed birds are more conspicuous and may attract predators more than black-headed birds. This supports predictions made by Goodale et al. [60] that species should avoid mixing with more conspicuous species as this increases the risk of detection by predators.

However, the purpose of vigilance is not only to detect predators but also to keep an eye on other group members, either to maintain cohesion or to avoid interference [61,62]. As red-headed Gouldian Finches are more aggressive than black-headed birds [37,48,63], birds in assemblages involving red-headed birds may pay more attention to conspecifics. The higher frequency of head movements in both, mixed-morph pairs as well as pure 
red-headed pairs lent support to this. In pairings involving red-headed birds, individuals not only scanned the environment for any changes but also kept an eye on the partner to spot early signs of approach and aggression, resulting in an increase in the frequency of head movements. Effects of competition on vigilance have also been found in other bird species. While Turnstones (Arenaria interpres) reduce vigilance when mixing with Purple Sandpipers (Calidris maritima) and Oystercatchers (Haematopus ostralegus) and also experience lower competition and aggression, Purple Sandpipers do not reduce vigilance in mixed flocks due to competition with other species [9,12]. Similar effects of competition on vigilance have been found in other taxa of mixed-species assemblages $[21,58,61,64]$.

Prediction 4 expected young birds to be more vigilant as they are more exploratory [40]. Higher vigilance has been found in bolder Pine Siskins, offsetting their higher costs of predation [15]. However, age did not affect vigilance in the Gouldian Finch. Therefore, there may be a trade-off between vigilance and information gathering.

In summary, Gouldian Finches used context-specific vigilance strategies, employing visual search strategies in familiar situations and visual tracking strategies in unfamiliar situations. Morphs did not differ in their vigilance. However, morph composition affected vigilance; pure black-headed morphs had lower vigilance than pairings involving redheaded birds. Higher group conspicuousness and/or higher risk of aggression may explain increased vigilance whenever red-headed birds are involved.

Supplementary Materials: The following are available online at https: / www.mdpi.com/article / 10.3390/birds2040030/s1, Table S1: The full data set.

Funding: This research received no external funding.

Institutional Review Board Statement: The study was conducted according to the guidelines of the Declaration of Helsinki, and approved by the Institutional Ethics Committee of Liverpool John Moores University (29 November 2017).

Informed Consent Statement: Not applicable.

Data Availability Statement: Data will be provided as a supplementary once the manuscript has been accepted.

Acknowledgments: I would like to thank Matthew Johnson for collecting all data for this study, Georgina Eccles for helping with the data collection, Blattner Heimtierfutter for sponsoring all bird food, Peter McGough and other breeders for donating some of the Gouldian Finches, the animal care technicians for looking after the birds and three anonymous reviewers for their comments.

Conflicts of Interest: The author declares no conflict of interest.

\section{References}

1. Baker, D.J.; Stillman, R.A.; Smart, S.L.; Bullock, J.M.; Norris, K.J. Are the costs of routine vigilance avoided by granivorous foragers? Func. Ecol. 2011, 25, 617-627. [CrossRef]

2. Watson, M.; Aebischer, N.J.; Cresswell, W. Vigilance and fitness in grey partridges Perdix perdix: The effects of group size and foraging-vigilance trade-offs on predation mortality. J. Anim. Ecol. 2007, 76, 211-221. [CrossRef]

3. Fairbanks, B.; Dobson, F.S. Mechanisms of the group-size effect on vigilance in Columbian ground squirrels: Dilution versus detection. Anim. Behav. 2006, 73, 115-123. [CrossRef]

4. Bertram, B.C.R. Living in groups: Predators and prey. In Behavioural Ecology: An Evolutionary Approach; Krebs, J.R., Davies, N.B., Eds.; Blackwell Scientific: Oxford, UK, 1978; pp. 64-96.

5. Stojan-Dolar, M.; Haymann, E.W. Vigilance of mustached tamarins in single-species and mixed-species groups-The influence of group composition. Behav. Ecol. Sociobiol. 2010, 64, 325-335. [CrossRef]

6. Beauchamp, G. Animal Vigilance: Monitoring Predators and Competitors; Elsevier: London, UK, 2015.

7. Ye, Y.; Jiang, Y.; Hu, C.; Liu, Y.; Qing, B.; Wang, C.; Fernández-Juricic, E.; Ding, C. What makes a tactile forager join mixed-species flocks? A case study with the endangered Crested Ibis (Nipponia nippon). Auk Ornithol. Adv. 2017, 134, 421-431. [CrossRef]

8. Stears, K.; Schmitt, M.H.; Wilmer, C.C.; Shrader, A.M. Mixed-species herding levels the landscape of fear. Proc. R. Soc. B 2020, 287, 20192555. [CrossRef]

9. Metcalf, N.B. Flocking preferences in relation to vigilance benefits and aggression costs in mixed-species shorebird flocks. Oikos 1989, 56, 91-98. [CrossRef] 
10. Favreau, F.-R.; Goldizen, A.W.; Fritz, H.; Blomberg, S.P.; Best, E.C.; Pays, O. Within-population differences in personality and plasticity in the trade-off between vigilance and foraging in kangaroos. Anim. Behav. 2014, 92, 175-184. [CrossRef]

11. Schmitt, M.H.; Stears, K.; Shrader, A.M. Zebra reduce predation risk in mixed-species herds by eavesdropping on cues from giraffe. Behav. Ecol. 2016, 27, 1073-1077. [CrossRef]

12. Metcalf, N.B. The effects of mixed-species flocking on the vigilance of shorebirds: Who do they trust? Anim. Behav. 1984, 32, 986-993. [CrossRef]

13. Periquet, S.; Valeix, M.; Loveridge, A.J.; Madzikanda, H.; Macdonald, D.W.; Fritz, H. Individual vigilance of African herbivores while drinking: The role of immediate predation risk and context. Anim. Behav. 2010, 79, 665-671. [CrossRef]

14. Beauchamp, G. Predator attack patterns influence vigilance in a virtual experiment. Behav. Ecol. Sociobiol. 2020, 74, 49. [CrossRef]

15. Pascal, J.; Senar, J.C. Antipredator behavioural compensation of proactive personality trait in male Eurasian siskins. Anim. Behav. 2014, 90, 297-303. [CrossRef]

16. Cresswell, W.; Quinn, J.L.; Whittingham, M.J.; Butler, S. Good foragers can also be good at detecting predators. Proc. R. Soc. B 2003, 270, 1069-1076. [CrossRef]

17. Barros, M.; Alencar, C.; de Souza Silva, M.A.; Tomaz, C. Changes in experimental conditions alter anti-predator vigilance and sequence predictability in captive marmosets. Behav. Proc. 2008, 77, 351-356. [CrossRef]

18. Shonfield, J. The effect of familiarity on vigilance behaviour in grey squirrels. McGill Sci. Undergrad. Res. J. 2011, 6, 45-49.

19. Coolen, I.; Giraldeau, L.-A. Incompatibility between antipredatory vigilance and scrounger tactic in nutmeg mannikins, Lonchura punctulate. Anim. Behav. 2003, 66, 657-664. [CrossRef]

20. Robinson, B.; Merrill, E.H. Foraging vigilance trade-offs in a partially migratory population: Comparing migrants and residents on a sympatric range. Anim. Behav. 2013, 85, 849-856. [CrossRef]

21. Randler, C. Vigilance of mallards in the presence of greylag geese. J. Field Ornithol. 2004, 75, 404-408. [CrossRef]

22. Fernandez-Juricic, E.; Gall, M.D.; Dolan, T.; O’Rourke, C.; Thomas, S.; Lynch, J. Visual systems and vigilance behaviour of two ground-foraging avian prey species: White-crowned sparrows and California towhees. Anim. Behav. 2011, 81, 705-713. [CrossRef]

23. Fernandez-Juricic, E. Sensory basis of vigilance behavior in birds: Synthesis and future prospects. Behav. Proc. 2012, 89, 143-152. [CrossRef]

24. Jones, K.A.; Krebs, J.R.; Whittingham, M.J. Vigilance in the third dimension: Head movement not scan duration varies in response to different predator models. Anim. Behav. 2007, 74, 1181-1187. [CrossRef]

25. Fernandez-Juricic, E.; Beauchamp, G.; Treminio, R.; Hoover, M. Making heads turn: Association between head movements during vigilance and perceived predation risk in brown-headed cowbird flocks. Anim. Behav. 2011, 82, 573-577. [CrossRef]

26. Krebs, H.; Weyers, P.; Macht, M.; Weijers, H.-G.; Janke, W. Scanning behavior of rats during eating under stressful noise. Physiol. Behav. 1997, 62, 151-154. [CrossRef]

27. Lazarus, J. The early warning function of flocking in birds: An experimental study with captive Quelea. Anim. Behav. 1979, 27, 855-865. [CrossRef]

28. Griesser, M. Nepotistic vigilance behavior in Siberian jay parents. Behav. Ecol. 2003, 14, 245-250. [CrossRef]

29. Arenz, C.L.; Leger, D.W. Antipredator vigilance of juvenile and adult thirteen-lined ground squirrels and the role of nutritional need. Anim. Behav. 2000, 59, 535-541. [CrossRef]

30. Monclus, R.; Roedel, H.G. Influence of different individual traits on vigilance behaviour in European rabbits. Ethology 2009, 115, 758-766. [CrossRef]

31. Beauchamp, G. The effect of age on vigilance: A longitudinal study with a precocial species. Behaviour 2018, 155, 1011-1024. [CrossRef]

32. Lea, A.J.; Blumstein, D.T. Age and sex influence marmot antipredator behavior during periods of heightened risk. Behav. Ecol. Sociobiol. 2011, 65, 1525-1533. [CrossRef]

33. Rieucau, G.; Blanchard, P.; Martin, J.G.A.; Favreau, F.-R.; Goldizen, A.W.; Pays, O. Investigating differences in vigilance tactic use within and between the sexes in Eastern grey kangaroos. PLoS ONE 2010, 7, e44801. [CrossRef]

34. Mathot, K.J.; van den Hout, P.J.; Piersma, T.; Kempenaers, B.; Reale, D.; Dingemanse, N.J. Disentangling the roles of frequency-vs. state-dependence in generating individual differences in behavioural plasticity. Ecol. Lett. 2011, 14, 1254-1262. [CrossRef]

35. Roche, E.A.; Brown, C.R. Among-individual variation in vigilance at the nest in colonial cliff swallows. Wilson J. Ornithol. 2013, 125, 685-695. [CrossRef]

36. Galeotti, P.; Rubolini, D.; Dunn, P.O.; Fasola, M. Colour polymorphism in birds: Causes and functions. J. Evol. Biol. 2003, 16, 635-646. [CrossRef] [PubMed]

37. Pryke, S.R.; Griffith, S.C. Red dominates black: Agonistic signalling among head morphs in the colour polymorphic Gouldian finch. Proc. R. Soc. B 2006, 273, 949-957. [CrossRef]

38. Boerner, M.; Krueger, O. Aggression and fitness differences between plumage morphs in the common buzzard (Buteo buteo). Behav. Ecol. 2008, 20, 180-185. [CrossRef]

39. Hurtado-Gonzales, J.L.; Baldassarre, D.T.; Uy, J.A.C. Interaction between female mating preferences and predation may explain the maintenance of rare males in the pentamorphic fish Poecilia parae. J. Evol. Biol. 2010, 23, 1293-1301. [CrossRef] [PubMed]

40. Mettke-Hofmann, C. The effect of head colour and age on personality traits in a social setting. Ethology 2012, 118, 906-916. [CrossRef] 
41. Costanzo, A.; Romano, A.; Ambrosinia, R.; Parolinia, M.; Rubolinia, D.; Capriolia, M.; Cortia, M.; Canovac, L.; Saino, N. Barn swallow antipredator behavior covaries with melanic coloration and predicts survival. Behav. Ecol. 2018, 29, 1472-1480. [CrossRef]

42. Huhta, E.; Rytkonen, S.; Solonen, T. Plumage brightness of prey increases predation risk: An among-species comparison. Ecology 2003, 84, 1793-1799. [CrossRef]

43. Karpestam, E.; Merilaita, S.; Forsman, A. Colour polymorphism protects prey individuals and populations against predation. Sci. Rep. 2016, 6, 22122. [CrossRef] [PubMed]

44. Bohls, P.; Koehnle, T.J. Responses of Eastern Gray squirrels (Sciurus carolinensis) to predator calls and their modulation by coat color. Am. Midl. Nat. 2017, 178, 226-236. [CrossRef]

45. Scriba, M.F.; Rattenborg, N.C.; Dreiss, A.N.; Vyssotski, A.L.; Roulin, A. Sleep and vigilance linked to melanism in wild barn owls. J. Evol. Biol. 2014, 27, 2057-2068. [CrossRef] [PubMed]

46. Dostine, P.L.; Johnson, G.C.; Franklin, D.C.; Zhang, Y.; Hempel, C. Seasonal use of savanna landscapes by the Gouldian finch, Erythrura gouldiae, in the Yinberrie Hills area, Northern Territory. Wildl. Res. 2001, 28, 445-458. [CrossRef]

47. Brush, A.H.; Seifried, H. Pigmentation and feather structure in genetic variants of the Gouldian finch, Poephila gouldiae. Auk Ornithol. Adv. 1968, 85, 416-430. [CrossRef]

48. Williams, L.J.; King, A.J.; Mettke-Hofmann, C. Colourful characters: Head-colour reflects personality in a social bird, the Gouldian finch (Erythrura gouldiae). Anim. Behav. 2012, 84, 159-165. [CrossRef]

49. O'Reilly, A.O.; Hofmann, G.; Mettke-Hofmann, C. Gouldian finches are followers with black-headed females taking the lead. PLoS ONE 2019, 14, e0214531. [CrossRef]

50. Pryke, S.R.; Astheimer, L.B.; Buttemer, W.A.; Griffith, S.C. Frequency-dependent physiological trade-offs between competing colour morphs. Biol. Lett. 2007, 3, 494-497. [CrossRef]

51. Greenberg, R.; Mettke-Hofmann, C. Ecological aspects of neophobia and neophilia in birds. Curr. Ornithol. 2001, 16, 119-178.

52. Mettke-Hofmann, C.; Rowe, K.C.; Hayden, T.J.; Canoine, V. Effects of experience and object complexity on exploration in garden wearblers (Sylvia borin). J. Zool. 2006, 268, 405-413. [CrossRef]

53. Inglis, I.R.; Langton, S.; Forkman, B.; Lazarus, J. An information primacy model of exploratory and foraging behaviour. Anim. Behav. 2001, 62, 543-557. [CrossRef]

54. Grünberger, S.; Leisler, B. Auswirkung der Umwelterfahrung auf die Neophobie der Tannenmeise (Parus ater). J. Ornithol. 1993, 134, 352-355. [CrossRef]

55. Morelli, F.; Benedetti, Y.; Diaz, M.; Grim, T.; Ibanez-Alamo, J.D.; Jokimaeki, J.; Kaisanlahti-Jokimaeki, M.-L.; Taette, K.; Marko, G.; Jiang, Y.; et al. Contagious fear: Escape behavior increases with flock size in European gregarious birds. Ecol. Evol. 2019, 9, 6096-6104. [CrossRef]

56. Ruiz Rodriguez, M.; Aviles, J.M.; Cuervo, J.J.; Parejo, D.; Ruano, F.; Zamora-Munoz, C.; Sergio, F.; Lopez-Jimenez, L.; Tanferna, A.; Martın-Vivaldi, M. Does avian conspicuous colouration increase or reduce predation risk? Oecologia 2013, 173, 83-93. [CrossRef] [PubMed]

57. van den Brink, V.; Dolivo, V.; Falourd, X.; Dreiss, A.N.; Roulin, A. Melanic color-dependent antipredator behavior strategies in barn owl nestlings. Behav. Ecol. 2012, 23, 473-480. [CrossRef]

58. Popp, J.W. Scanning behavior of finches in mixed-species groups. Condor 1988, 90, 510-512. [CrossRef]

59. Cords, M. Vigilance and mixed-species association of some East African forest monkeys. Behav. Ecol. Sociobiol. 1990, 26, 297-300. [CrossRef]

60. Goodale, E.; Ruxton, G.D.; Beauchamp, G. Predator eavesdropping in a mixed-species environment: How prey species may use grouping, confusion, and the cocktail party effect to reduce predator detection. Front. Ecol. Evol. 2019, 7, 141. [CrossRef]

61. Pays, O.; Ekori, A.; Fritz, H. On the advantages of mixed-species groups: Impalas adjust their vigilance when associated with larger prey herbivores. Ethology 2014, 120, 1207-1216. [CrossRef]

62. Beauchamp, G. On how risk and group size interact to influence vigilance. Biol. Rev. 2019, 94, 1918-1934. [CrossRef]

63. Pryke, S.R. Fiery red heads: Female dominance among head color morphs in the Gouldian finch. Behav. Ecol. 2007, 18, 621-627. [CrossRef]

64. Zhang, J.; Zhang, H.; Liu, Y.; Lloyd, H.; Li, J.; Zhang, Z.; Li, D. Saltmarsh vegetation and social environment influence flexible seasonal vigilance strategies for two sympatric migratory curlew species in adjacent coastal habitats. Avian Res. 2021, 12, 39. [CrossRef] 